\title{
InSTRUCTIONAL DESIGN AND FACILITATION as Contributors to Social Presence in Asynchronous Online Discussion Forums
}

\author{
Erica L. Demler, Stephanie Nardozzi, \\ Mark Bloxsom, and Deborah Moore-Russo
}

Erica L. Demler (ericadem@buffalo.edu), Stephanie Nardozzi (sln5@buffalo.edu), and Mark Bloxsom (markblox@buffalo.edu) are doctoral candidates in the Department of Learning and Instruction, University at Buffalo, The State University of New York, 505 Baldy Hall, Buffalo, NY 14260. Deborah Moore-Russo (dam29@buffalo.edu) is Associate Professor in the Department of Learning and Instruction, University at Buffalo, The State University of New York, 566 Baldy Hall, Buffalo, NY 14260.

\begin{abstract}
The purpose of this study is to identify factors that impact discussion in asynchronous online learning environments through the use of the Community of Inquiry framework (Garrison, Anderson, \& Archer, 1999). Various facets of teaching presence related to the design and facilitation of online discussion activities are considered in conjunction with common indices from social network analysis. Social presence is measured at two different levels; individual social presence is concerned with each participant's prominence
\end{abstract}


in, influence over, and control of the discussion, while group social presence looks at the volume and diversity of connections that occur between students within each forum. Cognitive presence is also addressed by exploring the external materials that participants introduced as they posted in discussions. Findings indicate that having students initiate their own thread within a forum leads to a more balanced discussion, while required (as opposed to optional) forums tend to have both a higher volume of communication and greater connectedness between participants. Facilitation of discussion, as a facet of teaching presence, supported students' cognitive presence. The information gained from this study will inform practices of asynchronous, online discussion-based courses offered at the postsecondary level.

Keywords: community of inquiry; online instruction; asynchronous online discussion.

DOI: http://dx.doi.org/10.15239/j.brcadvje.2018.03.01.ja02

\section{INTRODUCTION}

Programs in higher education across the country are at a crossroads as traditionally seated courses are transitioning to online alternatives. A common feature of many online courses is the use of asynchronous discussion forums as a means for students to interact with the instructor, each other, and the course content. Indeed, researchers have shown that online discussion forums have the potential to promote student skills such as knowledge construction, critical thinking, and problem solving (An, Shin, \& Lim, 2009) but only when the activities are properly designed and facilitated by the instructor in such a way as to elicit high engagement (Jo, Park, \& Lee, 2017). While general consideration has been given to the role of the instructor in online settings, An and colleagues (2009) asserted that little attention is often devoted to specific instructional strategies that can increase the effectiveness of online discussion. For this reason, our research focuses on those facets of design and facilitation that impact student interaction and learning in asynchronous online discussions. 


\section{LITERATURE REVIEW}

Over a decade ago, Kim and Bonk (2006) recognized that the ability to facilitate learning in online environments would become an essential skill for teachers; this certainly rings true today as online courses have become increasingly popular at all levels of instruction. The rise in popularity has brought with it a substantial amount of research related to teaching and learning in online settings. A major focus of this research has been asynchronous online discussion forums and the challenges associated with their implementation, such as encouraging interactions between students in order to help them develop a sense of community with their peers. In exploring the role of teachers in online discussions, Pawan, Paulus, Yulcin, and Chang (2003) found that instructional design decisions made by the teacher greatly impacted both student interactions and their ability to create meaning and confirm understanding.

According to Garrison, Anderson, and Archer (1999), students and teachers in online courses must form a community of inquiry (COI) in order to generate worthwhile educational experiences. Teaching presence, social presence, and cognitive presence are the three core elements in a $\mathrm{COI}$, and learning is said to occur as a result of the interaction between these three elements.

Teaching presence is defined as "the design, facilitation, and direction of cognitive and social processes for the purpose of realizing personally meaningful and educationally worthwhile learning outcomes" (Anderson, Rourke, Garrison, \& Archer, 2001, p. 5). Akyol and Garrison (2008) identify three categories of teaching presence that are evident in a community of inquiry: (a) design and organization, (b) facilitation of discourse, and (c) direct instruction. In this study, we consider the first two categories. For an online discussion forum, design and organization refer to the structure of the forum (i.e., amount and timing of required posts/responses), the topic of discussion, and the nature of the prompt used to generate discussion (e.g., questions provided vs. general reflection). Facilitation of discourse is related to the instructor's level of involvement in the forum, 
which should decrease over time as students become able to sustain discussion on their own (An, Shin, \& Lim, 2009). Direct instruction refers to instructional decisions and actions meant to direct student focus and address any issues that arise (Akyol \& Garrison, 2008).

Social presence, the second element in a COI, refers to "the ability of participants to identify with the group or course of study, communicate purposefully in a trusting environment, and develop personal and affective relationships progressively by way of projecting their individual personalities" (Garrison \& Akyol, 2013). The categories of social presence as listed by Joksimović and colleagues (2015) include interpersonal communication, open communication, and cohesive communication. Online classes often bring together students who have had very little to no prior experience with each other and hence do not automatically represent an established community (Gasson \& Waters, 2011). Social presence is fostered through teaching presence (Joksimović et al., 2015; Rogers \& Lea, 2005); so, the choices an instructor makes regarding the design and facilitation of online discussion can directly influence the levels of interpersonal, open, and cohesive communication that are evident in a discussion forum.

Cognitive presence, the third element in a COI, refers to the extent to which participants within a group are able to make meaning and come to a deeper understanding through communication. The four categories of cognitive presence as listed by Akyol and Garrison (2008) include triggering event, exploration, integration, and resolution which are indicated by a "sense of puzzlement," the exchange of information, the connection of ideas, and the application of new ideas. Cognitive presence relates to how students are able to move through the learning process; it is "a vital element in critical thinking, a process and outcome that is frequently presented as the ostensible goal of all higher education" (Garrison, Anderson, \& Archer, 1999, p. 89).

Each elements carries with it its own significance, but the most powerful learning occurs when all three elements are present and a true 
COI is formed. Ryman, Burrell, and Richardson (2009), while studying transformative learning in online environments, found that critical discourse within a group is necessary for its members to generate new knowledge. Knowledge generation is indicative of cognitive presence. In order for critical discourse to occur, however, they argue that a strong sense of community (social presence) must first be in place, which in turn results from effective leadership (teaching presence). Students are more likely to take risks and challenge established knowledge when they know they are supported within their learning community; it is the responsibility of the instructor to create that supportive environment (Ryman, Burrell, \& Richardson, 2009).

The purpose of this study is to identify factors that impact discussion in asynchronous online learning environments. More specifically, we explore variations in teaching presence within and across two virtual COIs to determine if and how those variations influenced the generated discussion. The following research questions guided the study:

1. How does teaching presence (as evidenced by the design and facilitation of discussion board activities) impact students' social presence in asynchronous online discussion forums?

2. How does teaching presence (as evidenced by the design and facilitation of discussion board activities) impact students' cognitive presence in asynchronous online discussion forums?

\section{MeTHOD}

\section{Participants and Setting}

The data were collected from two sections (Section A and Section B) of an online, asynchronous course that served as an introduction to doctoral studies in a department focused on preK-16 education. Study participants (13 from Section A and 16 from Section B) had all been admitted relatively recently to a doctoral program in curriculum, instruction, and learning at a public research university in the northeast 
U.S. The content areas of the 29 participants varied; the largest group of students (seven students) were in mathematics education, with the next highest group (three students) in elementary education. Other participant content areas included educational policy, online education, and music education, among others. Students were given both required and optional assignments. Students' grades in the course were determined by the number of points they compiled. Thus, they had a choice as to which and how many optional assignments to complete.

While there were other assignments in the course, this research focuses only on the students' posts to required and optional discussion forums. Course "readings" came from a textbook, other documents, and websites. Topics for weekly readings varied from information addressing issues in the field of education (e.g., public vs. private schools, financing schools) to information related to scholarly work (e.g., specific expectations of the program, general guidelines for educational research, information related to research dissemination venues).

At the beginning of the course, students were given a general directive to contemplate, extend, explore and/or push back on ideas raised by peers or in the readings to mimic a conversation that would occur in a faceto-face learning environment. Each reading also had a specific prompt. Readings from the textbook tended to have short instructional prompts for discussion, since this was already built into the text's readings. Here is an example prompt from an optional discussion forum related to a textbook reading: Complete the reading (pp. 49-86 of course text) and then make at least four posts to the related discussion forum. At least two of the posts should be in response to a peer. Other readings tended to have slightly more explicit directions on how to start the discussion. Still, they were rather vague. Here is the instructional prompt for one required forum that represents the tone of non-textbook reading prompts: Make at least four posts to the related discussion forum. At least two of these should be comments to peers' posts. This forum should identify and address issues related to the common sections of a research paper. While there are 
some general sections, note there may be some differences in expectations of different journals and different content areas. It is acceptable to raise these issues in this forum.

The course instructors for the two sections had co-planned the course, used the same course structure, materials, assignments, and grading, and implemented almost identical instructional interaction on the forums. By instructional design, each section instructor responded to every participant and on every thread at least once in the first discussion forum. The instructors posted comments or extending questions to about a third of the threads for the second forum, to about a fourth of the threads for the third forum, and then only to a few (zero to three) posts on all subsequent forums. For each forum, instructors would summarize the discussion and provide additional resources via emails sent to the students after the discussion forum closed. To ensure that conversations were taking place between students, the instructors purposefully refrained from always responding to posts and would share information as needed via a separate e-mail communication. By design each instructor was a heavy poster at the beginning of the course as students introduced themselves but quickly weaned away from participating in the discussion forums intentionally to ensure that more interactions occurred amongst the students and that student-student relationships were built.

\section{Data Coding and Analysis}

Two coders (both with at least five years' experience working in online learning environments) worked simultaneously for approximately eighteen hours in four separate sessions to record the following information for each discussion forum: total number of posts and threads, total number of participants, whether the forum was required or optional, how many times external material was referenced and/or shared in the forum, and how many participants shared this external material. They also recorded counts for person-to-person interactions, both as incoming and outgoing. 
Social network analysis (Borgatti, Everett, \& Johnson, 2013; Scott, 2000) via UCINET was used to examine person-to-person interactions in each forum at both the individual and group levels, as recommended by Jo, Park, and He (2017). The following common indices from social network analysis were used to measure social presence at the individual level: in-degree centrality or IDC (i.e., the number of responses a participant receives), out-degree centrality or ODC (i.e., the number of responses a participant sends), and betweenness or BTW (i.e., a measure of the degree to which a participant serves as a bridge connecting others in discussion). Each index correlates to one of the three categories of social presence identified above. IDC relates to interpersonal communication and is considered an indicator of a participant's prominence in the forum. ODC is representative of open communication and speaks to the influence a participant has on the discussion. BTW is indicative of cohesive communication and signifies the control a participant holds over others and their connections (Scott, 2000).

Three additional indices were used to explore interactions at the group level: average degree (mean number of connections, both IDC and ODC, per participant per forum), density (extent to which all possible connections between each participant are present), and connectedness (percentage of pairs of participants who were linked in some way across the network of possible connections). These indices can be used to assess the online discussions (Jo, Park, \& He, 2017), as they speak to the volume of communication and the diversity of connection types that are generated within a forum.

The existing literature regarding analysis of online asynchronous discussions has incorporated a vast diversity of coding schemes (WeltzerWard, 2011). The majority of these schemes have focused on the application of the Community of Inquiry model to discussions through descriptive measures of the style and purpose of specific statements. Social Network Analysis (SNA) was chosen for this research as a novel means to quantify the interactions between participants as well as the development 
of a communication network in general. The beauty of SNA is that it is a tool that has long been used by sociologists to study and describe the patterns in social interactions that are frequently not evident in more traditional methods of analysis (Scott, 2000). The use of SNA has become an increasingly popular method of analysis for both traditional communication networks as well as online communications. This includes a growing number of instances where SNA has been applied to online teaching and learning (Ouyang \& Scharber, 2017).

\section{Results}

\section{Preview Complete}

This completes the limited preview of this paper. Please visit the link below to purchase.

\section{Citation Information}

Demler, Erica L., Stephanie Nardozzi, Mark Bloxsom, and Deborah MooreRusso. "Instructional Design and Facilitation as Contributors to Social Presence in Asynchronous Online Discussion Forums." BRC fournal of Advances in Education 3, no. 1 (2018): 15-30. http://dx.doi.org/10.15239/ j.brcadvje.2018.03.01.ja02

\section{Web Appendix}

A web appendix for this paper is available at: http://dx.doi.org/10.15239/ j.brcadvje.2018.03.01.wa02 